\section{Eqüidade em saúde nos relatórios das conferências nacionais de saúde pós-Constituição Federal brasileira de 1988}

\author{
Equity in health according to reports by the \\ Brazilian National Health Conferences since \\ enactment of the 1988 Federal Constitution
}

\begin{abstract}
Based on a literature review and taking into account a concept of equity and its application to the field of public health, this article discusses the meaning ascribed to the term "equity" and its variations in the reports by the $9^{\text {th }}, 10^{\text {th }}$, and $11^{\text {th }}$ National Health Conferences in Brazil. Qualitative methods and content analysis were used to evaluate the approach to equity in two products the Conferences intended to formulate: analysis and presentation of the country's health profile and guidelines for public health policies. Little progress in understanding the issue of equity in health was observed; the predominant discourse was vague or excessively broad. The proposals were generic and nonspecific, failing to define the target problems and social groups.
\end{abstract}

Equity; Health Conferences (SUS); Health Policy
Marcelo Cardoso Pinheiro ${ }^{1}$

Márcia Faria Westphal 1

Marco Akerman 2

\section{Introdução}

As Conferências Nacionais de Saúde, assim como as de Educação, foram instituídas em 1937, numa reorganização do Ministério da Educação e Saúde Pública pela Lei no 378. Esta medida visava a "facilitar ao Governo Federal o conhecimento das atividades concernentes à educação e à saúde realizadas no País e orientá-lo na execução dos serviços locais de educação $e$ saúde, bem como na concessão de auxílio e subvenção federal" 1 (p. 61). Entretanto, a 1a Conferência Nacional de Saúde só ocorreu em 1941 e a 2a Conferência em 19501.

A institucionalização e a realização da primeira conferência ocorreram durante o Estado Novo de Vargas (1930-1945), época caracterizada por uma tendência acentuada de consolidação do poder central, que buscava a organização do serviço público uniformizado por um padrão nacional. Já o período desenvolvimentista (1946-1964), quando ocorreu a 3a Conferência Nacional de Saúde, permitiu uma experiência de exercício de democracia e de um federalismo efetivo, com tendência descentralizante no relacionamento da União com os níveis subnacionais de governo, mas não trouxe mudanças profundas na natureza do sistema de saúde. Este processo foi oficialmente interrompido pela Revolução de 1964, e nos subseqüentes 20 anos de ditadura militar ocorreram a 4ạ, 5a, 6a e 7a Conferências Nacionais de Saú- 
de, contraditoriamente mantendo o espaço de discussão da Reforma Sanitária. Nesse período ocorreram tentativas de concretização de modelos de descentralização, por iniciativa da academia e dos organismos internacionais, sendo que os modelos de medicina previdenciária continuaram a resistir à descentralização e a se orientar para cuidados médicos individuais. A implementação das Ações Integradas de Saúde (AIS) em 1983 foi a primeira tentativa de unificação e descentralização do Sistema de Saúde concretizada, em consonância com as discussões ocorridas nas Conferências mencionadas 2,3.

A 8a Conferência Nacional de Saúde foi convocada em 1986 para subsidiar a Assembléia Nacional Constituinte na nova Constituição e leis subseqüentes. Nessa conferência foram expressas as propostas construídas ao longo de quase duas décadas pelo chamado "movimento sanitário" e que serviram de base para a nova Constituição Federal brasileira, promulgada em 1988, como "um conjunto de princípios $e$ diretrizes extraídos não da prática corrente e hegemônica, mas propondo uma nova lógica organizacional" 4 (p. 81).

Existe um consenso sobre o importante papel dessa Conferência que assumiu a tarefa de definir os princípios doutrinários que deveriam nortear a Constituição Federal. Foi nesse documento que se explicitou a saúde como um direito de todos os cidadãos brasileiros e dever do Estado, fornecendo um ordenamento jurídico para a concretização deste direito. Além desse princípio defendido na 8a Conferência e incorporado na Constituição, destacamos os seguintes outros: participação da população na administração pública e descentralização por meio do fortalecimento do papel do município.

O relatório da 8a Conferência é bastante conciso, o que aponta para a existência de consenso entre os participantes, sem deixar de destacar aspectos polêmicos como a natureza do novo Sistema Nacional de Saúde, se estatizado ou não, de forma imediata ou progressiva. Mas de fato, o consenso almejado era de aspecto doutrinário, onde se buscou definir os princípios que deveriam nortear as reformas políticas desejadas, sem contudo, enfrentar a diversidade de propostas quanto às formas de implementação. Alguns desses princípios como integralidade e universalidade foram estabelecidos naquele momento, e posteriormente incorporados na Constituição Federal de 1988, já acompanhados do reconhecimento da necessidade de se definir prioridades, demonstrado pela indicação de "começar pelas áreas carentes ou totalmente desassistidas" (Ministério da Saúde. 8a Conferência Nacional de Saúde; 1987. p. 385).
As Conferências Nacionais de Saúde a partir desses dois marcos, a 8a Conferência e a Constituição Federal de 1988, que estabelecem a direção doutrinária da política brasileira de saúde, passam a ter uma nova institucionalidade: a de canal de participação social na gestão do SUS. O governo e os representantes da sociedade civil exercem sua função política de forma paritária, mediados pelos princípios da Reforma Sanitária Brasileira - universalidade, integralidade e eqüidade - para desempenhar oficialmente as seguintes funções: definição da situação atual de saúde do país e elaboração das diretrizes de políticas públicas para a saúde (Lei 8.142. Diário Oficial da União 1990, 31 dez.).

Os eventos das Conferências adquiriram dimensões expressivas de público, conforme explicitado nos próprios relatórios. A 9a Conferência foi realizada com "quase 3 mil Delegados e Participantes Credenciados e mais de 1.500 Observadores, nacionais e internacionais"; na 10a Conferência Nacional de Saúde a representação se deu por " 1.260 delegados provenientes das Conferências Estaduais de todos os Estados da União e do Distrito Federal, antecedidas por quase 3.000 Conferências Municipais de Saúde”, além de participarem "também delegados de entidades nacionais, 351 convidados e 1.341 observadores"; e na 11a Conferência Nacional de Saúde, “... delegados e delegadas presentes a esta Conferência, 2.500 homens e mulheres de diferentes classes sociais, credos, idades, raças e etnias de todas as regiões do país ...”.

É certo que para dar respostas ao complexo sistema político-administrativo brasileiro, organizado em Municípios, Estados e União, e trabalhar com a diversidade representada por milhares de pessoas, oriundas de localidades com realidades muito díspares e diferentes atores do sistema de saúde, as Conferências precisariam manter uma engenharia organizacional que objetivasse a consecução de resultados a partir de seus objetivos. As Conferências, em seu papel de ator coletivo, podem legitimar posições contraditórias do governo, se não for consubstanciado um resultado final das Conferências, afinal, mais de 5 mil pessoas têm opinando sobre o SUS por meio de um número excessivo de proposições.

Este trabalho não se propõe a fazer uma análise histórica dos contextos políticos das Conferências ou do seu papel como ator social. Seu objetivo é focalizar as Conferências Nacionais de Saúde a partir de dois grandes marcos, a Constituição Federal de 1988 e a Lei 8.142, como uma das instituições que configuram o Sistema de Saúde e realizar uma análise crítica dos relatórios, para verificar como foi sendo 
apropriado o conceito de eqüidade em saúde, pelas 9ạ, 10a e 11 $\underline{a}$ Conferências Nacionais de Saúde.

\section{Eqüidade em saúde}

A palavra equidade no aspecto semântico está bastante próxima à palavra igualdade, podendo até constar como seu sinônimo. A etimologia de ambas revela o mesmo elemento formador, "equ-", antepositivo do latim "aequus" que pode significar unido, justo, imparcial ou favorável. Enquanto a palavra eqüidade é um vocábulo formado no próprio latim, a palavra igualdade é introduzida em língua de cultura 5.

No mundo contemporâneo, de flagrantes desigualdades sócio-econômicas, a saúde pública, como campo de conhecimento responsável pela teorização da intervenção humana no estado de saúde das populações e sua promoção, traz a discussão sobre desigualdade justa, da teoria política para o campo da saúde, por meio do conceito de eqüidade em saúde.

Almeida 6 destaca duas importantes dimensões que devem ser consideradas na abordagem da eqüidade em saúde: as desigualdades nas condições de vida e saúde e as desigualdades no acesso e consumo de serviços de saúde. As duas dimensões têm determinantes intra e extra setoriais geralmente cumulativos, mas os mecanismos para sua superação são distintos.

Whitehead 7 destaca a dimensão ética e moral em sua abordagem de eqüidade em saúde, quando se refere a diferenças evitáveis e desnecessárias e que também podem ser consideradas injustas. Para sua análise devem ser consideradas as variáveis biológicas, as culturais ligadas aos hábitos e costumes, a capacidade de escolha inclusive em função do nível de renda, exposição à insalubridade e condições de vida e trabalho exaustivas, acesso inadequado a serviços públicos essenciais de saúde, ou outros. Pontua, que se a doença não pode ser evitada, a mobilidade social expressa na tendência das pessoas doentes descerem na escala social deve ser considerada prevenível e injusta.

Kadt \& Tasca 8 destacam a multiplicidade de variáveis que permitem comparações entre grupos sociais para se identificar e avaliar as iniqüidades em saúde sob diferentes ângulos. Para os autores, o tipo de variável determina que tipo de grupo parece menos privilegiado e assim, um alvo em potencial para intervenções, pois adotar a eqüidade como um princípio requer concentrar-se nos mais necessitados.

Consultando-se como está ordenada a produção científica no campo da saúde, na base de dados MEDLINE o termo eqüidade não apa- rece como descritor, mas encontram-se outros termos utilizados para comparar diferentes situações de saúde, tais como: acessibilidade, justiça social, estado de saúde, fatores socioeconômicos e pobreza.

Na base de dados LILACS encontra-se eqüidade em saúde como descritor, subdividido em equidade na cobertura, na distribuição de usos e recursos com uma subdivisão de eqüidade financeira, no acesso e no estado de saúde, onde "eqüidade implica":

(a) As condições de saúde, redução de diferenças evitáveis e injustas até o mínimo possível;

(b) Os serviços de saúde, recebimento de atenção em relação à necessidade e contribuição na capacidade de pagamento.

A multiplicidade de linhas de pesquisa sobre eqüidade em saúde em desenvolvimento em várias universidades, com abordagens quali-quantitativas, e a pluralidade de indicadores para mapear as desigualdades sociais, a exclusão e iniqüidades em um território, levam ao reconhecimento das dificuldades da comunicação dos trabalhos científicos. A este respeito afirma Westphal 9 (p. 226), “ $a$ incompatibilidade intelectual entre pesquisadores, a complexidade dos fenômenos pesquisados e o relativismo intelectual confundem os leigos quanto à veracidade das informações científicas". Portanto, a aproximação entre o conhecimento científico e a administração pública deve estar na agenda da organização das Conferências, para que ao valor moral do conceito de eqüidade se incorpore um instrumental capaz de dar objetividade às análises e proposições para a gestão do sistema de saúde.

Desta forma, assim como saúde, eqüidade em saúde deve ser entendida como um estado determinado por múltiplos fatores e sua mensuração se dá por comparação a parâmetros estabelecidos. Para este estudo, o conteúdo das abordagens sobre eqüidade em saúde se consolida pela explicitação de parâmetros que permitam a comparação de grupos sociais em relação a dadas necessidades com repercussão no estado de saúde. A construção da eqüidade em saúde assume dimensão política quando analisados os padrões científicos e morais aceitáveis que prevalecem em determinado Estado, aqui entendido "ao mesmo tempo como um fato social e uma ordem, que procura atingir seus fins com eficácia e justiça" 10 (p. 2).

Se a eqüidade como valor ético pode ser considerada a mais política das virtudes, não se pode ignorar, como afirma Florentino 11 (p. 6), que "não teríamos uma sociedade se reproduzindo de maneira tão excludente e ao mesmo tempo com alto grau de estabilidade se não ti- 
véssemos o comprometimento de todos, ricos e pobres, com a exclusão social". Não há dúvida que a ruptura com a reprodução das iniqüidades em saúde requer uma postura bastante pró-ativa dos organizadores e dos participantes das conferências, e que a partir de uma ética de responsabilidade, se faça uma reflexão crítica desses três relatórios como resultados das respectivas Conferências, em função de seus objetivos.

\section{Metodologia}

A metodologia desta pesquisa é qualitativa e a técnica utilizada foi análise de conteúdo de documentos. Buscou-se verificar o conteúdo da abordagem da eqüidade em saúde nos relatórios das 9ạ, 10 e 11a Conferências Nacionais de Saúde, levando em conta seus objetivos de apresentar uma avaliação da saúde no país e diretrizes para políticas públicas.

Para Bardin 12, a análise de conteúdo é um conjunto de técnicas de análise do processo de comunicação, que permite o estudo das motivações, atitudes, valores, crenças e tendências. Seria uma metodologia voltada a uma hermenêutica controlada, baseada na inferência e na dedução. Um esforço de interpretação que oscila entre o rigor da objetividade e a fecundidade da subjetividade.

Foram analisados os conteúdos das proposições e avaliações dos relatórios que utilizavam os termos eqüidade ou de mesma raiz. Os termos encontrados foram: eqüidade, equalizando, equalização, eqüitativo, equânime(s), iniqüidade(s), equanimidade. Também foram incluídas outras unidades de texto dos relatórios para complementar a análise do conteúdo em relação à eqüidade em saúde

Para análise do conteúdo, das proposições de diretrizes de políticas públicas e do quadro de saúde apresentados em relação à eqüidade, entendeu-se que seria necessário o cumprimento de duas condições. Primeiro, a verificação do destaque de um ou mais grupos sociais a quem a questão ou a proposta se dirigia. Isto possibilitaria a comparação entre os grupos ou dos grupos com o conjunto brasileiro, a relação da parte com o todo ou entre as partes, e a identificação de desigualdades injustas. Procurouse verificar se a definição desses grupos sociais se dava em função de aspectos biológicos - patologias ou deficiências físicas - ou sociais - nível de renda, trabalho, região de moradia. A segunda condição que deveria ser atendida seria a definição de necessidades, a abordagem de demandas, que sendo atendidas, levaria à re- dução da desvantagem. Conforme a literatura, as alternativas de resposta às demandas seriam na oferta de serviços, na distribuição de recursos ou no acesso a bens e serviços.

Foi elaborado um quadro síntese apresentando os resultados, com base no qual foi aprofundada a análise do texto dos relatórios. O quadro apresenta o termo eqüidade ou semelhantes utilizados nos relatórios, e abre espaço para colocação do número de vezes que foram utilizados com especificação ou comparação de grupos sociais a que se dirigem, e outro espaço para contabilizar o número de vezes que foram utilizados com a especificação de um problema ou demanda de um grupo.

\section{Resultados e discussão}

A observação dos dados da Tabela 1 mostra o aumento gradativo das vezes que o termo eqüidade ou semelhante foi utilizado. Entende-se que existe uma conjunção de motivos que podem justificar este aumento, como a própria consolidação do conceito de eqüidade em saúde no campo de conhecimento das ciências da saúde. Para a ampliação do uso do termo eqüidade podem ter contribuído as transformações em termos de tecnologia da comunicação, características do processo de globalização, que dão visibilidade às desigualdades relacionadas à ocorrência dos riscos à saúde nas sociedades contemporâneas, como violência, uso de álcool e drogas e outros fenômenos.

Segundo Kluckhohn 13 (p. 214), nas diversas culturas "todas as reações que se tornam habituais são 'boas', do ponto de vista do organismo", considerando cultura como um conjunto de hábitos, costumes e valores. A questão primordial deste trabalho foi dar uma interpretação às "reações habituais" presentes nos três últimos relatórios das Conferências Nacionais de Saúde em relação a um valor específico: a eqüidade em saúde.

Se na cultura política brasileira as relações pessoais são tão privilegiadas, assim como o personalismo e a hierarquização da sociedade, conforme sua proximidade com os centros de poder, como então discutir eqüidade numa perspectiva de justiça social e impessoalidade? $\mathrm{O}$ fato de se considerar a sociedade brasileira como um "sistema social no qual convivem diferentes concepções de sociedade, de política, de economia" 14 (p. 85), aponta para a necessidade de confluência de conceitos para que o foro das Conferências Nacionais de Saúde possa cumprir efetivamente as funções de elaborar um quadro de saúde e diretrizes para políticas 
Os termos "eqüidade" ou semelhantes encontrados nos relatórios das 9ạ, 10ạ e 11ạ Conferências Nacionais de Saúde e a verificação das vezes em que foram utilizados explicitando-se grupos sociais e demandas.

\begin{tabular}{lccc}
\hline & 9ạ Conferência & 10ạ Conferência & 11ạ Conferência \\
\hline Termos encontrados & Eqüidade (2) & Eqüidade (8) & Eqüidade (25) \\
& Equalizando (1) & Equânime(s) (4) & Equânime (3) \\
& Eqüitativo (1) & Iniqüidaidade (1) & Equalização (1) (3) \\
& & Equanimidade (1) & 32 \\
Total & 4 & 14 & 2 \\
Especificação de grupos sociais & 0 & 1 & 1
\end{tabular}

Fonte: Relatórios das 9ạ, 10ạ e 11ạ Conferências Nacionais de Saúde.

de saúde. Este será o foco da observação das análises que são apresentadas a seguir.

\section{9ạ Conferência Nacional de Saúde}

A 9ạ Conferência foi realizada em 1992 após muita pressão e seis anos, não quatro anos conforme período de intervalo definido pela Lei 8.142 de 1990, após a 8a Conferência Nacional de Saúde, durante o governo de Fernando Collor de Mello, que defendia a diminuição das responsabilidades públicas em relação à saúde, inclusive com propostas de revisão constitucional. Fez ainda, vários vetos à Lei 8.080, a maioria deles relacionados ao princípio da "participação da comunidade”.

O tema principal da Conferência foi a "municipalização" e teve em parte o objetivo de contribuir para a implementação deste processo da descentralização da saúde, chamando a atenção sobre riscos de mudanças nos preceitos do SUS. Propôs a avaliação do controle social, indicando a criação dos Conselhos de Saúde nos estados e municípios, onde estes ainda não estivessem estruturados sendo consideradas as experiências locais na discussão nacional 15.

No relatório dessa Conferência (Ministério da Saúde. Relatório final da 9a Conferência Nacional de Saúde; 1992) a avaliação da situação da saúde no país apresentada caracterizou-se pela amplitude e subjetividade, sem apontar diferenças entre grupos sociais, como pode ser observado no seguinte trecho: "completo desrespeito à vida, evidenciado pelos inaceitáveis indicadores de saúde: baixa expectativa de vida, alta mortalidade infantil, alta mortalidade materna, elevado grau de desnutrição infantil ...” (p. 17).

Nas proposições do mesmo relatório, encontra-se o termo "equalizando" utilizado para a defesa da aposentadoria por tempo de serviço.
Nas duas vezes em que apareceu o termo “eqüidade", apenas a dimensão moral foi explicitada, sem uma direção objetiva, como mostra o exemplo: "assegurar que toda a rede contratada pratique a universalidade e eqüidade, obedecendo aos critérios de hierarquização" (p. 24).

Em seguida, encontra-se o termo "eqüitativa” numa utilização ainda mais nebulosa: “(...) necessidade imperiosa, particularmente na atual conjuntura de nosso país, face às investidas de interesses privatizantes contrários à distribuição eqüitativa da renda nacional e dos beneficios sociais" (p. 33).

Certamente, muitas interpretações e justificativas podem ser dadas a esta passagem, sem contudo, poder-se afirmar objetivamente quais são as investidas de interesses privatizantes ou qual seria a distribuição eqüitativa da renda nacional a que os participantes se referem.

Um aspecto que sempre demonstrou a grande iniqüidade do sistema de saúde brasileiro foi o formato de sistemas públicos fechados. Este fato foi abordado no relatório da seguinte maneira: "os sistemas públicos fechados, como é o caso do serviço de saúde dos militares - forças armadas e político militares - e de certos grupos de servidores públicos, também têm de ser incorporados ao SUS" (p. 28).

Entretanto, na explicitação desta questão não foi utilizado o termo eqüidade nem mesmo em sua dimensão moral. Talvez isto tenha ocorrido para não se entrar em choque com posicionamentos, como os observados nos trechos de relatórios apresentados a seguir, impregnados de viés fortemente corporativista em grande parte dos temas incluídos na pauta das Conferências, onde são focalizados especialmente os problemas dos trabalhadores da saúde. Destacaram-se proposições específicas como estas: "que se proíba a remuneração ba- 
seada na produtividade, definindo-se salários dignos e criação de adicionais por condições especiais de trabalho - local, distância, turno, etc - $e$ adicional de desempenho" (p. 30). "Estender aos aposentados os benefícios salariais dos profissionais da ativa" (p. 31).

Não se trata de negar legitimidade a todas as reivindicações, mas apontar que tal proposta enfraquece, porque divide, a abordagem política do direito à saúde. A luta por salários dignos e adicionais tem o foco numa categoria profissional, e não nas iniqüidades em geral, não contribuindo para garantir ou validar a dimensão política da saúde como um direito. As proposições mostram como fica difícil manter uma unidade de proposições estando o relatório aberto a pressões de grupos com maior capacidade de organização e pressão, como por exemplo, os aposentados do SUS.

\section{0ạ Conferência Nacional de Saúde}

A 10a Conferência foi realizada em 1996, no segundo ano do governo Fernando Henrique Cardoso. A Conferência ocorreu logo depois da crise do México que teve conseqüências na retomada do desenvolvimento econômico, dificultando investimentos sociais. A Conferência teve a direção do Professor Dr. Adib Jatene como Ministro da Saúde, um incentivador da participação social no processo de tomada de decisão em saúde.

O processo de descentralização já tinha avançado bastante, envolvendo novos atores e contextos locais diversos, com o conseqüente deslocamento e pulverização do processo decisório. Neste ano foram implementadas medidas de incentivo para que os municípios assumissem a gestão da rede de serviços locais de saúde, expressas na Norma Operacional Básica 96 (NOB 96) 16.

O controle social e a participação já se encontravam numa fase mais consolidada dentro do SUS, o que possibilitou um melhor preparo dessa Conferência. Ela foi precedida por 27 Conferências Estaduais e mais de 3 mil Conferências Municipais, sendo 1.260 delegados provenientes das Conferências Estaduais.

É importante ressaltar que no relatório dessa Conferência (Ministério da Saúde. Relatório final da 10a Conferência Nacional de Saúde; 1996) não se encontrou nenhum capítulo que se pudesse classificar como descrição do quadro atual de saúde da população do Brasil. Apenas o objetivo de apresentar deliberações foi incorporado neste relatório.

Encontrou-se uma maior recorrência de termos relacionados ao tema deste artigo: eqüi- dade aparece oito vezes; equânime(s), quatro; iniqüidade e equanimidade, uma. Estas ocorrências entretanto, na grande maioria das vezes expressou a questão da eqüidade de maneira geral e inespecífica, como mostra o seguinte exemplo: "4. Defender um Estado público e solidário através de (...). 4.5. Fortalecimento do seu papel de promotor da eqüidade" (p. 15).

Nesse relatório tratou-se do problema ainda persistente de hospitais estatais prestando serviços apenas a alguns cidadãos, que certamente não se encontram entre os mais necessitados, aproximando-o do princípio da eqüidade, como mostra o exemplo: "40. Os hospitais e ambulatórios da Rede Sarah e universitários, além dos governamentais que ainda se mantêm fechados ou restritivos aos usuários do SUS, como aqueles das Forças Armadas, Polícias Militares e Institutos de Previdência de Servidores, devem se incorporar ao SUS de modo gradual e responsável, subordinando-se aos princípios constitucionais de universalidade, eqüidade, regionalização e hierarquização" (p. 26).

A percepção de que o princípio da eqüidade deve gerar intervenções concretas, em alguns momentos parece estar mais presente, como o pleito da inclusão da linguagem de sinais como disciplina curricular para: “(...) a preparação de profissionais aptos à atenção dos portadores de deficiência auditiva, tanto nos Serviços de Saúde como na escola, para proporcionar-lhes oportunidades mais equânimes de acesso à escolarização e ao mercado de trabalho" (p. 20).

A proposição anterior foi a única desse relatório a focalizar um grupo em desvantagem, no caso, o grupo de portadores de deficiência auditiva, junto ao apelo moral da eqüidade, em contraposição às outras vezes, em que a generalização dá o tom, como no exemplo que se segue: “285. O Ministério da Saúde e as Secretarias Estaduais e Municipais de Saúde devem romper com o modelo de assistência individual, fragmentada, curativa e hospitalocêntrica e implantar a Atenção Integral à Saúde (....). Devem ser assegurados o repasse do poder e dos recursos até o nível local, a regionalização, a hierarquização e a eqüidade, garantindo às populações urbanas e rurais o acesso a todos os níveis de atenção e a qualquer ação de que necessitem" (p. 71).

Assim como em outros diversos trechos encontra-se o uso de expressões que indicam uma valorização da retórica e uso de chavões, sem perceber-se um avanço no debate em relação à eqüidade em saúde.

De fato, muitas vezes a Conferência parece ser um espaço onde não ocorrem problematizações, como se vê neste exemplo: “351. O Minis- 
tério da Saúde deve apresentar ao Conselho $\mathrm{Na}$ cional de Saúde no prazo de 180 (cento e oitenta) dias (...) uma proposta de Política Nacional de Assistência Farmacêutica integrada aos princípios do SUS. Essa politica deve:” (...) “351.4. Assegurar assistência farmacêutica técnica e cientificamente fundamentada com critérios de eqüidade, qualidade e efetividade, para suporte das ações de diagnóstico e tratamento, com uso racional de todo e qualquer medicamento necessário, enfocando as necessidades da população $e$ garantindo a resolutividade das ações" (p. 84).

Reproduzem-se idéias com a simplicidade de manuais e transferem-se as responsabilidades de propor diretrizes para outras instâncias institucionais.

Talvez por que nessa Conferência muitos participantes estão na condição de Conselheiros de Saúde de seus estados ou municípios, percebe-se uma atuação bastante clara no fortalecimento institucional dos Conselhos de Saúde, assim como do papel dos conselheiros, como mostram os exemplos a seguir: "os participantes da 10a Conferência Nacional de Saúde deliberaram pelo aprofundamento e pelo fortalecimento do Controle Social, reafirmando a obrigação dos Gestores de cumprirem a legislação do SUS também no que se refere ao caráter permanente e deliberativo dos Conselhos de Saúde na formulação e no controle da execução da política de saúde (...)” (p. 41).

"119. As Comissões Intergestores Bipartite e Tripartite devem ter suas funções claramente definidas, não devendo avançar sobre as funções deliberativas dos Conselhos de Saúde e submeter suas proposições às decisões dos mesmos" (p. 43).

Estas afirmações demonstram um viés corporativista ou tratam os Conselhos como meras instâncias de exercício de poder, desviando-se do sentido público para o qual foram criados, isto é, de ser um canal de participação política, inclusive mais equânime para os diversos segmentos da sociedade brasileira. Estas proposições parecem privilegiar enfoques puramente hierárquicos ao invés de uma abordagem mais cooperativa e solidária, dando a impressão de se privilegiar o controle e não uma participação real de cidadãos nas decisões políticas.

O trecho seguinte exemplifica bem como a ética da responsabilidade fica ausente em vários momentos: "197. O Ministério, Secretarias Estaduais e Municipais de Saúde devem criar mecanismos legais, para que os Conselhos Municipais de Saúde tenham controle sobre os credenciamentos e pagamentos feitos via a Tabela de Procedimentos do SUS (SIH, SIA e SIOP (...)” (p. 56).

Ao invés dos participantes das Conferências apresentarem diretrizes, conforme seu pa- pel institucionalizado, para que os Conselhos tenham efetivo papel deliberativo sobre o sistema de saúde, transfere-se o debate e a responsabilidade ao Ministério, Secretarias Estaduais e Municipais de Saúde.

Nesse relatório encontra-se uma ênfase ainda maior nas questões trabalhistas. Os seguintes exemplos de deliberações corroboram a afirmação:

“227. (...) implantação de jornada de 30 horas com regime de plantão não superior a 12 horas e da manutenção da aposentadoria por tempo de serviço com salário integral" (p. 61).

“227.8. (...) assegurando o mesmo tratamento também no que se refere a vale-transporte, ticket-alimentação, auxílio-creche, e outras conquistas trabalhistas" (p. 61).

"245. Os Gestores do SUS devem estender aos aposentados todos os ganhos do pessoal em atividade, conceder aposentadoria integral dos servidores do SUS aos 25 anos de serviço" (p. 63).

Os exemplos acima comprovam a exagerada ênfase dada aos interesses específicos dos trabalhadores de saúde, onde a postura predominante é de defesa da categoria profissional, havendo um afastamento dos conferencistas do papel de agentes públicos. Além disto, algumas dessas proposições como aposentadoria aos 25 anos de serviço ou jornada de trinta horas, podem ser interpretadas como conquista de um privilégio. Entende-se que a exacerbação da luta por conquistas trabalhistas nas Conferências rouba espaço do diálogo em torno das atuais concepções de eqüidade em saúde.

\section{1ạ Conferência Nacional de Saúde}

A 11ạ Conferência Nacional de Saúde foi realizada em 2000, no segundo governo Fernando Henrique Cardoso, quando a situação econômica do país poderia ser descrita como de crise. A nossa moeda - o Real - havia se desvalorizado, o crescimento econômico estagnado criava uma conjuntura desfavorável à geração de emprego, além de outros problemas. Seu relatório recebeu o título: "efetivando o SUS: acesso, qualidade e humanização na atenção à saúde, com controle social".

No final do ano 2000, 99\% dos municípios brasileiros estavam enquadrados em alguma das duas modalidades de gestão definidas pelo Ministério da Saúde. Foi também neste ano que foi promulgada a Emenda Constitucional 29, que definiu um patamar para aplicação de recursos públicos no financiamento das ações e serviços de saúde nos orçamentos da União, Estados e Municípios 17.

O relatório dessa Conferência (Ministério da Saúde. Relatório final da 11ạ Conferência Na- 
cional de Saúde; 2000) apresenta um espaço bastante amplo em relação ao objetivo de apresentar um quadro da saúde no país, com a designação de cenário.

Nesse relatório encontra-se o termo eqüidade 25 vezes; equânime, três; iniqüidade(s), três e equalização, uma, apresentando uma maior centralidade do conceito em relação à saúde, mesmo que ainda apenas como um valor moral. Não se encontra um avanço na utilização do mesmo como um critério para elaboração de propostas, predominando ainda avaliações excessivamente vagas e subjetivas, como no exemplo a seguir:

"Para os participantes da 11a Conferência Nacional de Saúde, os serviços especializados têm gargalos que exigem a intervenção dos gestores para garantir a eqüidade da atenção, de acordo com a necessidade de cada usuário do sistema (...)" (p. 8).

O mesmo pode-se afirmar deste outro trecho: "o Brasil ainda não tem um modelo de atenção à saúde adequado, que atenda aos problemas de saúde no país com eqüidade. Os modelos vigentes mantêm caráter assistencialista, sendo incapazes de responder às necessidades da população. São modelos obsoletos, curativistas, assistencialistas (...)” (p. 11).

A avaliação com abordagem qualitativa, nesse relatório, abriu ainda mais espaço para uma linguagem com excessos retóricos, expressos no uso de palavras terminadas com o sufixo (istas) como "privatistas", "curativistas", "assistencialistas". É dada uma conotação negativa a atribuições fundamentais de qualquer modelo de atenção à saúde, como a assistência e a cura, além de não apresentar encaminhamentos para os problemas.

O trecho seguinte permite destacar dois aspectos relevantes: “2. Reverter a percepção do Ministério Público de que a questão central do SUS é a igualdade de acesso, o que vem fazendo com que muitas vezes o gestor acate proposituras do Ministério Público e decisões do judiciário que, do ponto de vista da eqüidade são extremamente injustas" (p. 19).

Primeiro, nesse relatório o Ministério Público aparece como um novo e importante ator em diversas colocações. Segundo, o relatório incorpora a questão do direito à saúde em sua dimensão legal, que nem sempre resultará em decisões mais justas e equânimes. No relatório encontrase o Ministério Público sendo convocado, ora pelos usuários, ora pelos gestores, demarcando a insipiência do debate entre estas duas categorias de participantes da Conferência.

A ausência de problematização pode ser verificada no seguinte trecho: "79. Os partici- pantes da 11a Conferência Nacional de Saúde reafirmaram a necessidade de fortalecer o caráter público das ações e serviços de saúde e a responsabilidade do Estado, definida na Constituição Federal, no provimento da saúde ao povo. Da mesma forma, os princípios da integralidade assistencial, da humanização e da eqüidade foram reiterados constituindo-se como objetivos para a consolidação do SUS” (p. 42).

Esta proposição pode ser considerada um mero conjunto de intenções, que não permite apontar os compromissos compartilhados pelos participantes das Conferências. O termo eqüidade aparece explicitado, mas nenhuma proposta é feita.

Verifica-se a tendência de eqüidade ser entendida como sinônimo de igualdade, como pode ser verificado no trecho seguinte:

“88. Assegurar a eqüidade na oferta de serviços de saúde para as populações urbana e rural coibindo qualquer forma de discriminação por parte dos prestadores, até mesmo as recepções diferenciadas" (p. 43).

A idéia de uma discriminação positiva, onde se evoque eqüidade para beneficiar quem precisa mais, parece não ter espaço nas resoluções. Mesmo quando são admitidas diferenças populacionais, não se avança para diretrizes que possam responder a estas questões para os grupos em desvantagem, como mostra o exemplo a seguir:

“i) Implementar programas de tratamento fora de domicílio, entendendo-o como um instrumento de equalização $e$ integralidade do acesso aos recursos necessários para o atendimento adequado de usuários residentes em localidades sem recursos assistenciais" (p. 47).

O exemplo anterior foi o único onde se encontrou o termo eqüidade aproximado à existência de um grupo populacional sem assistência.

Nesse relatório, no Cenário, diagnosticou-se como sendo a política de recursos humanos "o maior problema para a gestão do SUS nos municípios” e reconheceu-se "uma polarização usuários versus trabalhadores de saúde". Nas 56 proposições agrupadas sob o tema não se encontram mais as solicitações trabalhistas que predominaram nas outras Conferências. Elas adquiriram o mesmo tom ascético de generalidade das demais proposições. O termo iniqüidade é utilizado da seguinte maneira:

“172. Denunciar a iniqüidade gerada pela estratégia de flexibilização da contratação de recursos humanos para o SUS, que resulta também em maior gasto" (p. 57). 


\section{Conclusão}

Embora nos relatórios das Conferências Nacionais de Saúde se tenham observado mudanças formais, poucos avanços foram constatados em relação à proposição de diretrizes. Este foi um achado também de Luz 18 , que identificou poucos acréscimos em termos de decisões e encaminhamentos no relatório da 9a Conferência, quando comparado ao relatório da $8 \underline{a}$ Conferência. Os dados desta pesquisa permitiram constatar o mesmo com os relatórios da 10a e 11ạ Conferências.

As Conferências vêm falhando no cumprimento dos objetivos de avaliar as condições de saúde da população e propor diretrizes de políticas públicas para resolver os problemas do país. Seus longos relatórios são elaborados com a inclusão maciça de considerações e proposições que nada mais são que repetições dos nossos princípios constitucionais, onde a retórica ascética toma o lugar dos objetivos das conferências.

O termo eqüidade é utilizado inicialmente poucas vezes e até de modo indevido. $\mathrm{O}$ tratamento do tema é incompleto, não destacando grupos sociais desfavorecidos e suas necessidades em saúde, o que indica uma resistência inicial à incorporação do conceito, como um critério para a elaboração das diretrizes de políticas públicas. O discurso a respeito da eqüidade permanece geral e amplo, apresentando avaliações e proposições vagas e inespecíficas.
Um dos motivos do desvio das funções das Conferências Nacionais de Saúde pós Constituição Federal brasileira de 1988, está provavelmente em privilegiar o tema dos direitos dos trabalhadores de saúde. Na 9ạ e 10a Conferências encontrou-se com bastante objetividade as solicitações trabalhistas e uma grande generalidade em relação a outras políticas e na 11a registrou-se a polaridade. A falha desta abordagem se dá pela impossibilidade de se conciliar o papel dos trabalhadores de saúde, enquanto categoria profissional com interesses particulares e de agentes públicos que atuam no interesse comum.

A ocorrência periódica das Conferências Nacionais de Saúde, que agregam 5 mil ou mais pessoas de diferentes segmentos da sociedade, por si só adquire uma relevância política que contribui para a efetivação e sustentabilidade do SUS. Se houver uma maior objetivação de seus propósitos, os efeitos sinérgicos deste espaço de debate e tomada de decisão, com a devida compreensão e problematização de prioridades, se multiplicarão. As Conferências além de terem o peso político de legitimar, poderão ser verdadeiros espaços de problematização e ampliação da consciência crítica, possibilitando a construção de alternativas inovadoras para o desenvolvimento social. Esta poderá ser, senão uma situação fácil, a necessária ao fortalecimento institucional das próprias Conferências Nacionais de Saúde.

\section{Resumo}

A partir de um posicionamento sobre o conceito de eqüidade e sua aplicação no campo da saúde pública, com base em revisão de literatura, o objetivo deste artigo é discutir o significado atribuído ao uso do termo eqüidade ou variações deste termo nos relatórios das $9 \underline{a}, 10 \underline{a}$ e 11a Conferências Nacionais de Saúde. Utilizou-se a metodologia qualitativa e a técnica análise de conteúdo para analisar a abordagem da questão da eqüidade nos dois produtos que as Conferências se propõem a formular: a apresentação de um quadro da saúde no país e diretrizes para as políticas públicas de saúde. Verificou-se que houve pouco avanço em rela- ção ao entendimento do tema eqüidade em saúde, com predomínio de um discurso com sentido vago ou excessivamente amplo. As proposições apresentadas foram caracterizadas também como gerais e inespecíficas, uma vez que na maior parte das vezes, não foram definidos grupos sociais a que as propostas se dirigiam ou o problema a ser enfrentado.

Eqüidade; Conferências de Saúde (SUS); Política de Saúde 


\section{Colaboradores}

M. C. Pinheiro elaborou o artigo. M. F. Westphal contribuiu em todo o trabalho, discutindo todos os itens antes e após as críticas e sugestões da revista. Colaborou mais especificamente na elaboração da introdução e conclusões. M. Akerman contribuiu na contextualização histórica das Conferências Nacionais de Saúde.

\section{Referências}

1. Campos JQ. Saúde em concordata. São Paulo: Editora Jotace; 1988.

2. Westphal MF. A participação popular e políticas municipais de Saúde: Cotia e Vargem Grande Paulista [Tese de Livre Docência]. São Paulo: Faculdade de Saúde Pública, Universidade de São Paulo; 1992.

3. Noronha JC, Levcovitz E. AIS-SUDS-SUS: Os caminhos do direito à saúde. In: Guimarães R, Tavares RAW, organizadores. Saúde e sociedade no Brasil: anos 80. Rio de Janeiro: Relume Dumará; 1994; p. 73-111.

4. Buss PM. Saúde e desigualdade: o caso do Brasil. In: Buss PM, Labra ME, organizadores. Sistemas de saúde: continuidades e mudanças. São Paulo: Editora Hucitec/Rio de Janeiro: Editora Fiocruz; 1995. p. 61-101.

5. Cunha AG. Dicionário etimológico Nova Fronteira da língua portuguesa. Rio de Janeiro: Editora Nova Fronteira; 1986.

6. Almeida C. Saúde e eqüidade nas reformas contemporâneas. Saúde Debate 2000; 54:6-21.

7. Whitehead M. The concepts and principles of equity and health. Copenhagen: World Health Organization; 1990.

8. Kadt E, Tasca R. Promovendo a eqüidade. Um novo enfoque com base no setor da saúde. São Paulo: Editora Hucitec; 1993.

9. Westphal MF. A universidade e as políticas públicas. In: Sorrentino M, organizador. Ambientalismo e participação na contemporaneidade. São Paulo: Educ; 2001.
10. Dallari DA. Elementos da teoria geral do Estado. São Paulo: Editora Saraiva; 1995.

11. Cariello R. Fim da mobilidade social ajudou Lula. Folha de São Paulo, 2002. Dez 30; Caderno A; 6.

12. Bardin L. Análise de conteúdo. Lisboa: Edições 70; 1997.

13. Kluckhon C. Antropologia: um espelho para o homem. Belo Horizonte: Itatiaia; 1963.

14. DaMatta, R. A casa \& a rua. In: DaMatta R, organizador. A questão da cidadania num universo relacional. Rio de Janeiro: Guanabara Koogan; 1991. p. 71-102.

15. Merhy EE. A mutilação da lei orgânica da saúde: vitória dos que desejam um povo mutilado. Saúde Debate 1991; 30:8-9.

16. Boldstein R. Atenção básica na agenda da saúde. Ciênc Saúde Coletiva 2002; 7:401-12.

17. Lucchese PTR. Eqüidade na gestão descentralizada do SUS: desafios para a redução de desigualdades em saúde. Ciênc Saúde Coletiva 2003; 8:439-48.

18. Luz MT. As Conferências Nacionais de Saúde e as políticas de saúde na década de 80. In: Guimarães R, Tavares RAW, organizadores. Saúde e sociedade no Brasil: anos 80. Rio de Janeiro: Relume Dumará; 1994. p. 131-52.

Recebido em 29/Out/2003

Versão final reapresentada em 17/Set/2004 Aprovado em 27/Set/2004 